\title{
Conceptualizing Destination Performance Evaluation for Internal Destination Benchmarking: A Review
}

Toney K Thomas*

\section{Abstract}

Benchmarking the performance of tourism in a tourist destination is an extremely complex and challenging task because of its interdisciplinary nature and due to the involvement of many sectors, components and elements. Integrating the different sectors and synergizing the tourism system function are major issues as the tourism industry requires different levels of involvement with diverse interests. Since tourism is one of the key areas of economic transformation in developing countries, it is essential to enhance destination image, positioning, and ultimately to achieve market leadership which can contribute significantly to communities and nations. It is important to evaluate the performance of the tourist destination in order to stabilize the growth of tourism in the most competitive and sustainable manner. This study explains the construction of Index Core Components and performance evaluation methods for internal tourist destination benchmarking using literature reviews. The findings revealed that a new conceptual model can be used by incorporating major sectors, components and elements of tourism to measure individual performance of the selected Index Core Components.

Keywords: Benchmarking, Destination, Leadership, Evaluation, Development, Measurement

* School of Tourism, Events \& Recreation, Taylor's University; tonythomas@taylors.edu.my 


\section{Introduction}

Since the tourism industry has been highly considered as an extradisciplinary beneficial sector of economic development, most of the countries are continually facing issues of sustainable development and management of tourism industry. Absolute sustainable development is yet to be practiced in any planned tourist destination even though it has been more than a decade, since the terms sustainability and sustainable development have been associated with tourist destination development. There is no significant reason for this issue other than the interdisciplinary nature of the tourism industry, which makes the sustainable tourism practices more complex. Even though public sectors, private sectors and NGO's are actively involved in promoting tourism in the most sustainable manner, the interdisciplinary nature of the tourism industry has been highly influencing the unsustainable tourism development in many countries. Dependency on tourism sectors has become significant in the current decade, and hence many countries' national economic development has directly depended on tourism industry. The economy of many countries is significantly over dependent on the tourism industry and in the past few years tourism trends show that the tourism industry is highly sensitive to the external and internal threats; due to this, turbulence is witnessed in many countries' tourist arrival and eventually it has affected the decreasing inflow in tourist receipts and the collapse of national and regional economies. What is required for destination development is a strong measurable tool which can explain the status of the tourism industry with individual identification of the best performing component and the areas that need significant improvement for stabilizing the tourism development. Therefore, the past, present and future of the industry can be accurately interpreted and forecasted. Knowing the position of tourist destination development internally is the first step to device strategies to overcome various developmental issues and make the tourism industry a market leader in the international tourism market. 


\section{Rationale}

Many tourist destinations adopt tourist satisfaction survey using satisfaction indices to measure the tourist satisfaction level. In fact, this method only helps to increase the service quality, while the tourism industry stands to support multiple sectors such as local community, service providers and the local government. Core components of these sectors need to be considered for destination performance evaluation. The emerging core destination management activity is the periodic monitoring of visitor satisfaction and the regular resource monitoring of other involved parties that are vulnerable to damage caused by tourism (Mathias \& Klaus, 2004). There is a significant gap of empirical studies investigating the level of most of the parties involved in tourism development. Lack of studies exists in considering the comprehensive and holistic model of measuring tourist satisfaction, community impact, tourism stakeholders' performance and managerial action for tourist destination development. Undoubtedly, there is a significant need to measure the level of involvement and action of all the parties involved in tourism development for destination competency as the industry is the amalgam of different sectors, subsectors, business components and performance elements. Hence, this study attempts to identify core performance components of the tourist destination for internal destination benchmarking.

\section{Benchmarking Concepts}

The concept of benchmarking originates from Deming's Quality Management Theory that aims to enhance quality of a product or service and check its sustainability (Kozak \& Nield, 2001). Benchmarking has been given many definitions by different organizations and authors, but it has not been critically discussed in the context of tourism (Kozak, 2004). Camp (1989) defined benchmarking as the search for industry best practices that leads to superior performance (Kozak, 2004). "Benchmarks are undoubtedly valuable in assessing the performance of the operations in one area or another of any hospitality or tourism business" (Leslie, 2001, p.128). Classification of benchmarking in tourism includes internal 
benchmarking, external benchmarking, generic benchmarking and competitive benchmarking. However, the basic step to performing external, generic and competitive benchmarking is to evaluate one's own performance through internal benchmarking. In tourism, measuring the internal performance of a tourist destination needs a multi-criteria approach as the industry is a blend of sectors, components and elements. Hence, tourist destination benchmarking is the evaluation of the performance of various elements of the tourism system. The ultimate idea of destination benchmarking is to device strategies for successful destination development by increasing economic multiplier, improved social contribution and maintenance of environmental values with a high level of tourist satisfaction, where minimal adverse impact is expected from the overall development.

\section{Internal Benchmarking}

The first and foremost step for destination benchmarking is selfassessment in terms of strength and weakness of a tourist destination without external and generic comparison. Cross \& Leonard, (1994) and McNair \& Leibfried, (1992) noted that internal benchmarking is an approach that includes the collection of data on one's own performance and its evaluation based on a set of indicators in all sectors of tourism (Kozak, 2004). The main purpose of internal benchmarking is to improve the performance of tourism business or tourist destination by identifying their own strengths and weaknesses by measuring the internal capability of a tourist destination.

\section{Strategic Destination Performance Evaluation}

Strategic destination performance is a systematic approach of identifying key performance strengths and weaknesses of tourism system elements and components. A superior synergy is required to establish the performance evaluation of the tourist destination. In an internal view Collis \& Montgomery (1995) noted that competitive advantage of a tourist destination stems from valuable resources that enable the destination to perform better at a lower cost than that of the competitors. It is stated that the resources must 
be valuable, rare, imperfectly imitable and non-substitutable and also must be scarce and directly transferable to the market (Rodriguez \& Diasz, 2007). Therefore, the customer (tourist) perceives the destination as an integral and differential offer, which facilitates the analysis of its principal strength and weakness (Rodriguez \& Diasz, 2007). This ultimately reaches a state of noncompetitiveness, where the destination can stop the competition by stopping the competitor. This is an alternative strategy for destination leadership. The internal analysis of tourist destination allows identifying its principal strengths and weaknesses (Rodriguez \& Diasz, 2007) that include all operational core components of the tourist destination.

\section{Destination Performance Core Components}

Since tourist system constitutes several performance components, it is impossible to consider all of them in the internal performance evaluation. However, the strategy is to identify key performance components of the destination that contributes significantly to the performance level of the tourist destination. These core components can be identified through Analytical Hierarchy Process (AHP). Analytical Hierarchy Process (AHP) is a multi-criteria decision making approach. It uses a multi - level hierarchical structure of objectives, criteria, sub criteria and alternatives. Its approach is a pair-wise comparison of data. These comparisons are used to obtain the weight of importance of decision criteria. Based on the AHP process, the following core components are identified as the key performance areas of a tourist destination.

\section{Performance core component 1}

Tourist Satisfaction Index: It is critically important for all tourist destinations to evaluate the tourist satisfaction level. "In doing so, a baseline of information from which to build and tailor marketing promotions and decision makers can better identify visitor markets that offer opportunities for growth" (Andriotis, Agiomirgianakis, \& Mihiotis, 2007). Malthouse et al., (2004) observed that customer satisfaction has long been valued as a key outcome of good marketing practice (He \& Song, 2008). Without question, service quality and customer satisfaction are key drivers of financial 
performance as customer satisfaction is directly linked to the tourist's emotion (McMullan \& O'Neill, 2010). Satisfaction variables or psychological construct of tourists are associated with motivation, satisfaction, and intention (Huang \& Hsu, 2009). "It is also argued that satisfaction leads to increased loyalty, reduced price elasticity, increased cross buying, and positive word of mouth" (Matzler \& Pechlaner, 2001, p.26). Hence, visitor satisfaction is a key measure for internal destination benchmarking.

\section{Performance core component 2}

Community Impact Assessment: The new agenda for tourism development significantly focuses on community development. Therefore tourism development needs to devise a strategy that the development meets the needs of the local community. This approach advocates tourism development with a commitment of ecologically responsible, socially compatible, culturally appropriate, politically equitable, technologically supportive and economically viable for the host community (Sirakaya \& Choi, 2005). Ap et al.(1992) suggested that destination communities are the major actors in the tourism development process since they are directly affected by it (Sirakaya \& Choi, 2005). Burns et al., (1999) suggested that lack of community involvement has been pointed as one of the main factors leading to a high rate of tourism plan failure (Yuksel \& Yuksel, 2008). According to Anderek et al., (2005) tourism is considered as a tool for economic transformation and in rural areas tourism can transform a poor society into a selfsufficient one. The literature on tourism impacts suggests that "a number of deleterious effects of tourism development such as environmental degradation, resource depletion and inauthentication, and commodification of host community cultures are the direct result of the philosophy on development" (Sirakaya \& Choi, 2005, p.381). Therefore, tourism development has positive and negative effects on destination community. What is required is minimizing the consequences of tourism development and maximizing the benefits and weighing them in a Cost Benefit Analysis (COBA) scale. 


\section{Performance core component 3}

Tour Operator's Perception: Tourists' decision making processes are complex, involving many sub-decisions, occurring continuously from prior to decision on 'where to go' through to 'what are we going to do now we are here' and beyond (Smallman \& Kevin, 2010, p.399). According to Sirakaya \& Woodside et al. (2005) the dominance of intangible factors in tourism is problematic (Smallman \& Kevin, 2010). The implementation of a specific code of conduct by tour operators has grown in popularity in recent years, and this is a clear indication that tour operators and supply chain have a significant role in the image and development of tourist destination (Gray, Reisinger, Jung, \& Brijesh, 2005). The role of a tour operator is to act as a negotiation point to create enjoyable moments in the tourist destination. Visitors expect high-quality facilities and customer service and these services are expected to be packaged by the tour operators (Blain, Levy, \& Ritchie, 2005) and their effort is indeed based on the benefits they get from tour operation. A simple idea is that a satisfied tour operator can enhance the image of the tourist destination. Following are the identified areas to focus tour operator's perception on tourism development for performance evaluation of tour operation core component.

- Issues of tour operation

- Comparative benefit and profit from tourism business

- Support of public sector

- Man power distribution

- Synergy between supply chains

- Tour Operators' recommendation

\section{Performance core component 4}

Managerial Action: Policy Implementation Effectiveness: Tourism Policy is a road map of tourism development, which contains the priorities and action plan showing the direction the tourism industry needs to grow. Tourism policy development is significantly considered as a managerial activity by the public sector organization representing the interest of the country's social 
and economic goals. Tourism policy is used to reflect a broader understanding of the political, societal and human context of public sector-led decision making (Airey \& Chong, 2010) and policy conceptualization is a holistic function of interactions and process in negotiation with all the parties directly or indirectly impacted from tourism development. Howlett et al. (2003) suggested that policy development process has to focus on the factors that affect policy formulation and implementation as well as the subsequent effect of the policy (Airey \& Chong, 2010). Therefore it is important to design, implement and evaluate the policy as it shows direction of successful destination development. The main objective of policy evaluation is to analyse the effectiveness of policy based on the vision and mission and how well the policy is aligned with two major performance core components of destination evaluation; they are (a) visitor satisfaction and (b) community (social) impact.

\section{Models, Theory and Construct Development}

\section{Expectancy-Disconfirmation model: Tourist Satisfaction Index (TSI)}

Expectancy-Disconfirmation model is a method commonly used in measuring tourist satisfaction. This method is explained in the Expectation Disconfirmation Paradigm (EDP) based on the equity theory that satisfaction results from the comparison between consumer inputs and outputs (Yuksel \& Yuksel, 2001). This model suggests expectation and disconfirmation are correlated as without expectation disconfirmation cannot occur (Yuksel \& Yuksel, 2001). This model suggests the tourists' rating of a particular service based on how much importance the guest is given to a particular tourist service. Based on Lieper's (1990) system theory, tourist satisfaction is the totality of travelers' satisfaction with each aspect of the whole system. This measurement consists of (a) Satisfaction with pre trip services including travel agent, hotel reservation, knowledge of the service providers, cost of the trip etc. (b) Satisfaction with services at the tourist destination such as richness of experience, problem free destination, check in time, cost of services etc. and (c) Satisfaction with transit route services that ensure problem free travel (flight services, ticket agents, bus drivers, transfer etc.). Based on this theory any dissatisfaction 
experience with any of these service aspects is likely to decrease a traveler's satisfaction. But this measurement is not very important in measuring destination competitiveness as the tourist generally separates the quality of service from their point of origin and tourist destination; moreover, benchmarking a tourist destination is based on competitiveness. Destination authorities have less control on the quality of services at the traveler generating region and tourists have a logical preference for changing the service at the origin point if they find that the services are poor. According to Oliver et al., (1993) emotions such as dissonance associated with service encounter play an important role in defining satisfaction and predicting future behavior intention (McMullan \& O'Neill, 2010). Based on this model, emotion and dissonance in visitor satisfaction are measured. Yuksel (2001) suggests that customer satisfaction measures should include components such as equity, attribution, value-percept, dissonance, contrast, comparison level, evaluative congruity and quality (McMullan \& O'Neill, 2010). Based on this there are four scales designed to measure tourist satisfaction, they are (1) Cognitive Emotional Satisfaction Scale (ESS) which encompasses the tourists' feelings while visiting a tourist destination, (2) Cognitive Product Satisfaction Scale (CPS) which measures the tourists' consumption experience on major tourism products, (3) Cognitive Service Satisfaction Scale (CSS) that measures the tourists' experience on different services in the tourist destination and (4) Cognitive Dissonance Scale (CDS) represents the mixture of favorable and unfavorable experiences at the tourist destination (McMullan \& O'Neill, 2010).

As per the literature review, it is important to measure the satisfaction level of tourists in various cognitive levels. Since the tourist satisfaction is fragmented in emotional level, service level, product level and dissonance level, the following conceptual framework is formulated. A simple interpretation of this model representing the Cognitive Dissonance of the tourist is the sum of the effect of emotional, product and service satisfaction during their trip. 


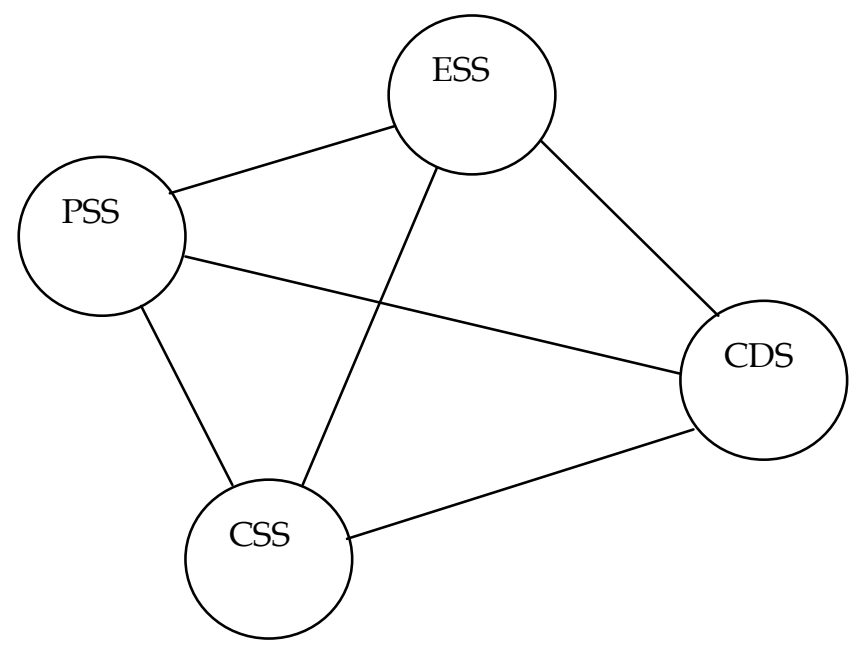

Figure 1. Conceptual Framework for Tourist Satisfaction Index (TSI)

\section{Social exchange theory: Community Impact Assessment (CIA)}

"In the examination of attitudes, researchers recognized that residents' attitude towards tourism is not simply the reflections of residents' knowledge about tourism impact but is also influenced by residents' values and personalities" (Wang \& Pfister, 2008, p.85). According to Anderek et al. (2005) social exchange theory has been frequently adopted in tourism studies as a theoretical framework for developing and understanding the residents' attitude toward tourism (Wang \& Pfister, 2008). Emerson (1976) observed that using social exchange theory offers a framework for examining the position an individual actor may take contingent upon a rewarding action from others (Wang \& Pfister, 2008). "A basic tenet set is that locals are likely to participate in an exchange if they believe that they are likely to gain benefits without incurring unacceptable costs" (Gursoy \& Rutherford, 2004) and "benefits are essentially in value domains, and in tourism, economic and non-economic values domain may influence an attitude toward tourism" (Wang \& Pfister, 2008, p.85). Non-economic value domains need to focus on the nature of conducting factors in the creation of value domains in which tourism is an emergent economic activity" (Wang \& Pfister, 2008, p.85). "Even when the practice of exchange engaged by residents is regarded as a pure economic activity, the non-economic value domains or benefits such as area development, improved 
standard of living, space value, access to infrastructure etc. in the exchange process cannot be ignored" (Wang \& Pfister, 2008, p.85). The theory further elaborates that residents are likely to support development as long as they believe that the expected benefits exceed costs. Based on this theory six exogenous constructs can be developed they are (a) Economic benefit (b) Economic cost (c) Social benefits (d) Social costs (e) Cultural benefits (f) Cultural costs (Gursoy \& Rutherford, 2004).

Based on the above facts the framework of Community Impact Assessment (CIA) consists of the constructs such as Economic Benefit, Economic Cost, Social Benefit, Social Cost, Cultural Benefits, Cultural Costs and Expecation of the Tourists. This is fragmented into six constructs such as Conservation Effort (CE), Social Issues (SI), Social Image (SIM), Social Service (SS), Economic Condition (EC) and Community Perception (CP). The conceptual framework is illustrated in the following figure.

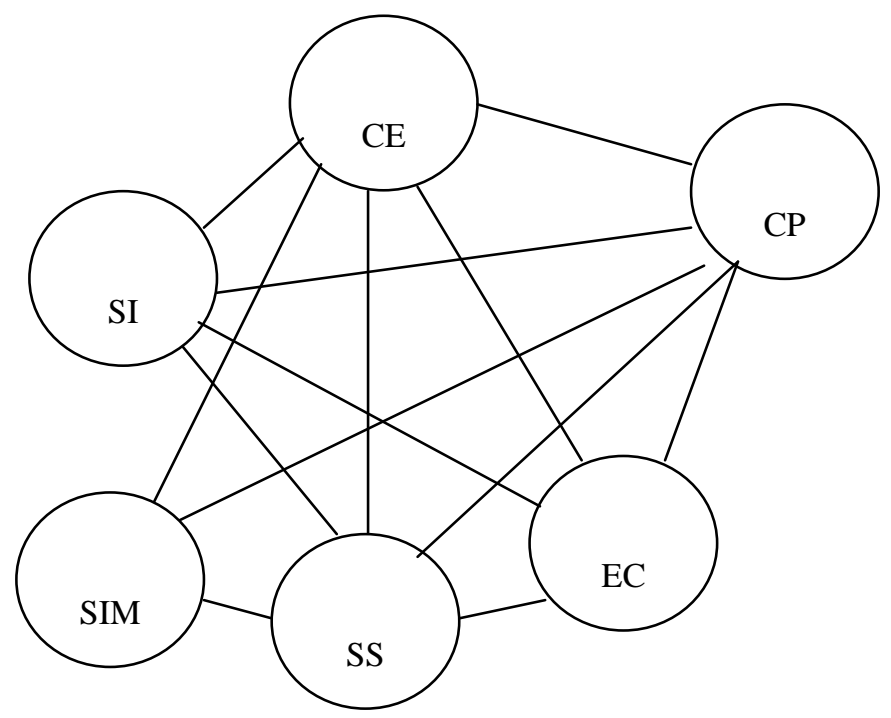

Figure 2. Conceptual Framework- Community Impact Assessment (CIA) 


\section{Stakeholder theory: Tour operators' perceptions}

The stakeholder theory is significantly applicable in various stakeholders' operations in the tourism sector. The basic concept of the definition of stakeholder theory is how an organization shapes its business concept. Since tourism is a product that consists of many components and elements, shaping tourism business involves multiple parties. Descriptive stakeholder theory explains how managers and stakeholders actually behave and how they view their actions and roles (Faintaine, Haarman, \& Schmid, 2006). Friedman (2006) explain the normative stakeholder theory that describes how managers or stakeholders should act and should view the purpose of organizations, based on some ethical principles (Faintaine, Haarman, \& Schmid, 2006). In tourism, the normative stakeholder theory is more emphasized due to the influence of normative principle on the stakeholder to enhance the sustainable development of the industry. Friedman (2006) further explains the theory, which says that stakeholders consisting of customers, employees, local communities, suppliers and distributors and shareholders (Faintaine, Haarman, \& Schmid, 2006). Lane (2003) "contributed to the application of the principle in tourism stressing the "plurality of organizational interest groups and the political nature of organizational goal setting and policy implementation" (Faintaine, Haarman, \& Schmid, 2006, p. 734). The theory strains the practice of stakeholders within the ethical framework of their day-to-day business operation that contributes significantly towards responsible, committed and yet competent tourism development. This will enhance the reputation of the tourism sector operation in the potential tourism market.

\section{Network Theory: Managerial Action}

Network theory in tourism describes the multiplier effect of the tourism policy. A better outreach will have extra mileage in the benefits of tourism development. Tourism policy implementation effectiveness is a Cost Benefit Analysis (COBA) of a series of network which is described as a 'waves repast' from a major managerial action. Social network theory explains social relationship in term of nodes and ties. Brass (2002) describes the mechanisms and processes that interact with network structures to 
yield certain outcomes for individuals and groups (Halgin \& Borgatti, 2011). The network consists of a set of actors or nodes along with a set of ties of a specified type (Halgin \& Borgatti, 2011, p. 2). Tourism policy is a network of many different actors involved and is also a mechanism that functions to achieve specified goals of involved parties. The involved parties are directly, indirectly visibly or invisibly involved in the effective implementation of tourism policy.

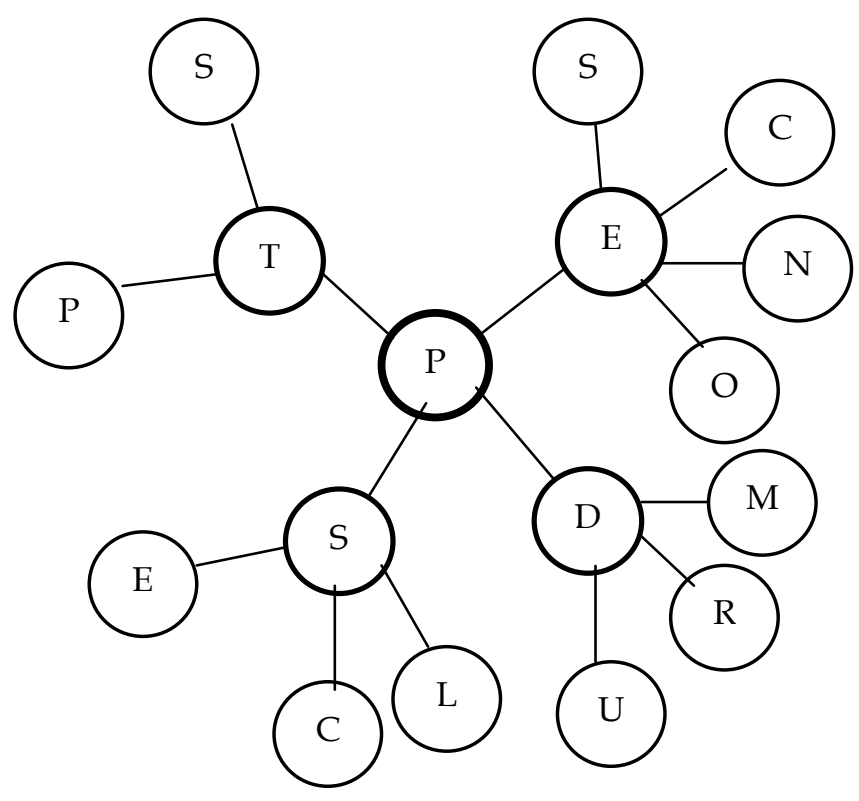

Figure 3. Nodes and Ties of Tourism Policy based on Network Theory

Tourism policy consists of a number of nodes and ties that are glued in the tourism industry network. Major nodes that are the key segment of the industry consists of (1) economy (E), this node is tied with major beneficial areas such as stake holders (S), community $(\mathrm{C})$, national economy $(\mathrm{N})$ and others $(\mathrm{O})$ are the indirect business entities in tourism business. (2) The tourists (T) are considered as the actors of the tourism system and the preference of a destination is based on the level of satisfaction (S) and confidence of their trip in terms of safety and security (protection) (P). (3) The society (S), as a multidisciplinary field of study and policy needs to consider social and cultural equilibrium 
(C) and environmental consideration (E). The $4^{\text {th }}$ component is destination development (D) which consists of marketing and promotion of tourist destination (M) and in order to be competitive, identification of new Resources (R) is important. Fischer \& Hammann (2005) note that the destination needs to differentiate them in an attempt to develop a competitive edge in the global market (Mei, Arcodia, \& Ruhanen, 2011) and hence, destination will be competitive only if it provides unique products which are the Unique Selling Points (USP) (U) of the tourist destination.

\section{Modeling Destination Performance Evaluation}

In order to operationalize the destination performance for internal destination benchmarking, the overall performance evaluation of tourist satisfaction, community impact, tour operators' perception and policy implementation effectiveness are measured. The recommended contemporary model is illustrated in figure 4 . (page.71)

\section{Implications}

Using the recommended destination performance evaluation model, there are multiple benefits expected from it. For the policymakers and Destination Management Organisation (DMO), the new perofrmance evaluation model will be a holistic tool to dignose the issues related to tourism development. Tourist destination performance evaluation also helps to enhance tourism performance in many ways. Firstly, identification of destination performance index core components and operational procedure helps to evaluate the preformance of any tourist destination despite its developmental status. Even though the Index Core Components remain the same for all internal destination benchmarking, the variables may differ based on the profile of the tourist destination. Different variables need to be set in each performance component based on the economic and social environment of the tourist destination; therefore an environmental scan is important to establish a benchmarking framework in a tourist destination. 


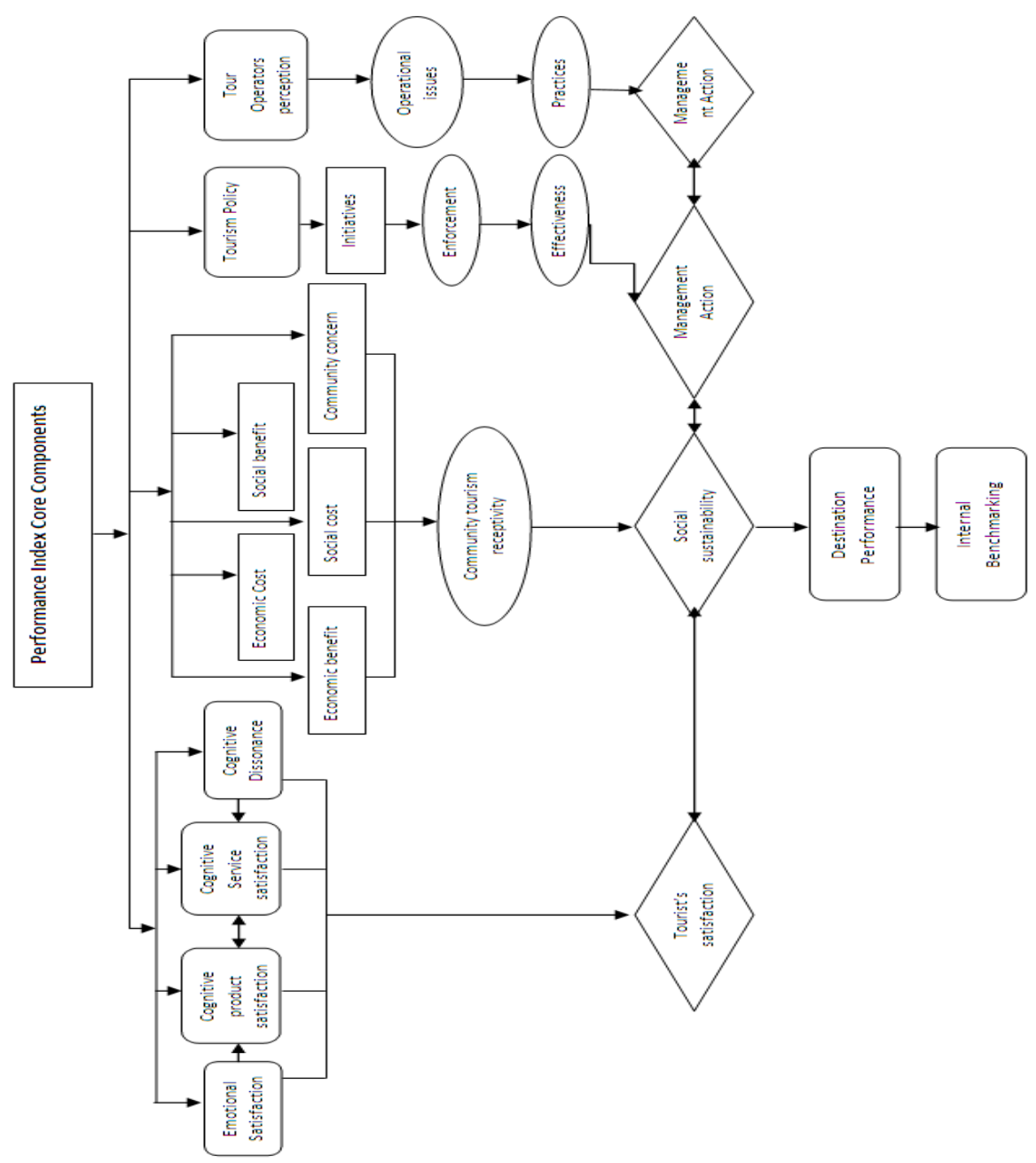

Figure 4. Destination Performance Evaluation Model 


\section{Implications}

Secondly, by evaluating the performance of the Index Core Component, the destination can evaluate the strengths and weaknesses of the tourist destination, hence appropriate action can be taken to enhance the performance of weak performing components. Thirdly, internal benchmarking though destination performance evaluation further contributes to standardize the operation and therefore absolute sustainability can be attained for long term growth of tourist destination. The output of internal benchmarking will be a foundational score for external, competitive and generic benchmarking.

\section{Conclusion}

The ultimate idea of this paper is to modify the traditional approach of evaluating the performance of a tourism destination and propose a new model. Based on the major role played by the different sectors of tourism, four measurable performance core components have been identified in internal benchmarking of a tourist destination. All these components have been then taken for the validation to perform internal destination performance evaluation. Considering the first component, tourist satisfaction, an index will be created to test the satisfaction of the tourist in two scales such as expectation and disconfirmation. In the case of Community Impact Assessment (CIA) component, variables will be selected based on the role of tourism in the destination community, this differ from one destination to another. In the case of stakeholders' performance, tour operators are considered as the measurement area, this is due to the fact that tour operators are the operation engine of tourism business. They are interlinked with tourism policy, political surroundings and business related to other stakeholders in the tourism industry. Managerial action is an important component to measure, as the tourism development is always a reflection of public sector priority. This priority will be reflected through the tourism policy of the tourist destination. The areas identified in policy measurements are the policy initiatives, action plan and effectiveness. Since the major performance components are identified, further study is needed to identify construction of variables and methods. In a general view 
destination performance evaluation for internal destination benchmarking needs to use holistic research methods consisting of quantitative and qualitative research. Tourist Satisfaction Index (TSI) and Community Impact Assessment will be measured quantitatively whereas Stakeholders perception and Managerial action will be measured qualitatively. The result of the measurement expects a superior synergy that glued in the four performance core components to reach a conclusion.

\section{Reference}

Airey, D., \& Chong, K. (2010). National Policy-Makers for Tourism in China. Annals of Tourism Research, 37(2), 295-314. doi: 10.1016/j.annals.2009.09.004

Andriotis, K. (2005). Community groups' perceptions of and preferences for tourism development: Evidence from Crete. Journal of Hospitality $\mathcal{E}$ Tourism Research, 29(1), 67-90. doi: 10.1177/1096348004268196

Andriotis, K., Agiomirgianakis, G., \& Mihiotis, A. (2007). Measuring tourist satisfaction: A factor-cluster segmentation approach. Journal of Vacation Marketing, 14(3), 221-235. doi: 10.1177/1356766708090584

Blain, C., Levy, E. S., \& Ritchie, B. (2005). Destination Branding: Insights and Practices from destination management organozations. Journal of Travel Research, 43(4), 328-338. doi: 10.1177/0047287505274646

Botti. L, N, P., \& Robinot E, S. B. (2009). Tourism destination competitiveness: The French Regions Case. 2 (1), pp. 6-20. European Journal of Tourism Research.

Faintaine, C., Haarman, A., \& Schmid, S. (2006). Stakeholder Theory, report of business.

Gray, P. L., Reisinger, Y., Jung, K. E., \& Brijesh, T. (2005). Do US tour operators' brochures educate the tourist on culturally responsible behaviours? A case study for Kenya. Journal of Vacation Marketing, 11(3), 265-284. doi: 10.1177/1356766705055719

Gursoy, D., \& Rutherford, G. D. (2004). Host Attitudes Toward Tourism: An Improved structural model. Annals of Tourism Research, 31(3), 495516. doi: $10.1016 /$ j.annals.2003.08.008

Halgin, S. D., \& Borgatti, P. S. (2011). On network theory. Organisation Science, 1-14. doi: 10.1287/orsc.1100.0641 
He, Y., \& Song, H. (2008). A Mediation Model of Tourists' repurchase intentions for packaged tour service. Journal of Travel Research, 47(3), 317-331. doi: 10.1177/0047287508321206

Kozak, M. (2004). Introducing destination benchmarking: A conceptual appraoch. Journal of Hospitality and Tourism Research, 28(3), 281-297. doi: $10.1177 / 1096348003256603$

Kozak, M. (2007). Tourist harassment: A marketing perspective. Annals of Tourism Research, 34(2), 384-399. doi: 10.1016/j.annals.2006.10.003

Kozak, M., \& Nield, K. (2001). An overview of benchmarking literature: Its strength and weakness. Journal of Quality Assurance in Hospitality $\mathcal{E}$ Tourism, 2(3), 7-23. doi 10.1300/J162v02n03_02

Leslie, D. (2001). Serviced accommodation, environmental performance and benchmarks. Journal of Quality Assurance in Hospitality $\mathcal{E}$ Tourism, 2(3), 127-147. doi:10.1300/J162v02n03_08

Mathias, F., \& Klaus, W. (20004). Destination benchmarking: An indicatorsystem's potential for exploring guest satisfaction. journal of travel research, 42, 212-225. doi: 10.1177/0047287503258827

Matzler, K., \& Pechlaner, H. (2010). Guest satisfactionbarometer and benchmarking: experience from Austria. Journal of Quality Assurance in Hospitality and Tourism, 2(3), 25-47. DOI:10.1300/J162v02n03_03

McMullan, R., \& O'Neill, M. (2010). Towards a valid and reliable measure of visitor satisfaction. Journal of Vacation Marketing, 16(1), 29-44. doi:10.1177/1356766709356141

Mei, Y. X., Arcodia, C., \& Ruhanen, L. (2011). A National government's tourism innovation initiatives: A review of tourism development policies in norway. Tourism: Creating a brilliant blend (pp. 1-19). CAUTHE.

Rodriguez, E. F., \& Diasz, R. M. (2007). A Model of Strategic Evaluation of a Tourism Destination Based on Internal and Relational Capabilities. Journal of Travel Research, 46(4), 368-380. doi: $10.1177 / 0047287507308324$

Rodriguez.M, D., \& Tomas.F, R. (2009). A Model of strategic ealuation of a toursm destination based on internal and relational capacities. 46, pp. 368-380. Journal of Travel Research. doi: 10.1177/0047287507308324

Sirakaya, E., \& Choi, C. S.-H. (2005). Measuring residents' attitude toward sustainable tourism: development of sustainable tourism attitude scale. Journal of Travel Research, 43(4), 380-394. doi: $10.1177 / 0047287505274651$ 
Smallman, C., \& Kevin, M. (2010). Process studies of tourists' decisionmaking. Annals of Tourism Research, 37(2), 397-422. doi: 10.1016/j.annals.2009.10.014

Wang, Y., \& Pfister, E. R. (2008). Residents' attitudes toward tourism and percieved personal benefits in rural community. Journal of Travel Research, 47(1), 84-93. doi: 10.1177/0047287507312402

Yuksel, A., \& Yuksel, F. (2001). The expectancy-disconfirmation paradigm: A Critique. Journal of Hospitality and Tourism Research, 25(2), 107-132. doi: $10.1177 / 109634800102500201$

Yuksel, F., \& Yuksel, A. (2008). Perceived clientelism: Effects on residents' evaluation of municipal services and their intensions for participation in tourism development projects. Journal of Hospitality $\mathcal{E}$ Tourism Research, 32(2), 187-2008. doi: 10.1177/1096348007313263 